Autor invitado

Silvia MagnaVaCCA

Universidad de Buenos Aires/CONICET

silmagna@ciudad.com.ar

\title{
El cuidado del amigo en la palabra y el silencio. El caso de Alipio
}

\section{The care of the friend in the word and in silence. The case of Alypius}

Resumen: Este breve trabajo se articula en tres partes: en la primera, y sobre la base de recientes trabajos sobre la ética medieval de los peccata oris, la autora se extiende sobre los extremos del multiloquium y la taciturnitas, con las respectivas caracterizaciones que de ellos hicieron los autores medievales y sus inmediatos antecedentes. Ubica, entonces, el uso sabio del officium locutionis entre esos extremos. En la segunda, se plantea la tradición ciceroniana sobre el concepto de amistad y su asunción y particular enriquecimiento por parte de Agustín. En la tercera parte hace confluir las consideraciones del arte de la palabra en el ejercicio de la amistad mostrando cómo Agustín concibe de hecho dicho arte en Confesiones VIII a propósito de su relación con Alipio.

Palabras clave: San Agustín, amistad, palabra, silencio.

\begin{abstract}
This brief work is structured as follows: in the first section, and relying on recent works on medieval ethics and peccata oris, the author deals with the extremes of the multiloquium and taciturnitas, touching on the different characterisations of them proposed by the medieval authors, as well as on their immediate antecedents. In this section, the author also places the wise use of the officium locutionis between the two aforementioned extremes. As for the second section, it contemplates the Ciceronian tradition regarding the concept of friendship and also its acceptance and later enrichment of this very concept by Augustine of Hippo. The third section deals with different considerations concerning the art of the word in the course of friendship while showing in what way Augustine in fact conceives such art in Confessions VIII when dealing with his relationship with Alypius
\end{abstract}

Keywords: Saint Augustin, friendship, word, silence.

Carla Casagrande y Silvana Vecchio, autoras de un conocido ensayo sobre los vicios capitales en la Edad Media, han dedicado también un volumen al tema de los peccata oris en la Edad Media. ${ }^{1}$ Examinan allí lo estudiado

Carla Casagrande y Silvana Vecchio: I peccati della lingua. Disciplina ed etica della parola nella cultura medievale, IEI Treccani, Roma, 1987. 
por los autores medievales sobre la blasfemia, la murmuración, la mentira, la vociferación, la maldición, el improperio, la detracción, la adulación, la jactancia, la burla, la bufonería y el lenguaje sucio. Se detienen, además, en un par de pecados de la palabra como el multiloquium y el vaniloquium, sobre los que quisiéramos demorarnos ahora.

¿Cómo traducir “multiloquium”?, ¿como "locuacidad” quizá?, ¿’ como "verborragia"? Puede ser. De hecho, ya Varrón había señalado la diferencia entre el que es elocuente y quien es, en cambio, meramente locuaz (eloquensloquax). ${ }^{2}$

Sea como fuere que se prefiera traducir este término, vayamos a su tratamiento en época patrística y particularmente en San Agustín. Sobre el final de su vida, el hiponense advierte el cúmulo de lo que él mismo ha dicho y escrito. Se inquieta, entonces, profundamente, ante una admonición del libro de los Proverbios que advierte que la verborragia no está exenta de pecado y que es prudentísimo quien impone moderación a sus labios: "In multiloquio non deerit peccatum, qui autem moderatur labia sua prudentissimus est". 3

No obstante, enseguida propone matices y lo hace nada menos que en el Prólogo de sus Retractaciones. La importancia de este texto como rendición final de la obra y aun de la vida agustiniana hace que debamos reparar en él. Dice al comienzo:

Este temor [el de haber pecado de verborragia] no se refiere a la vastedad de mi producción escrita o a lo mucho que, aun sin haber sido dictado por mí en vistas de una publicación, ha sido transferido de mi exposición oral a obras escritas. Es necesario precaverse de la acusación de multiloquium cuando lo que se dice es lo que es necesario decir, sea cual fuere la extensión de las intervenciones. Con todo, me infunden temor estas palabras de la Sagrada Escritura cuando considero que, de las múltiples discusiones en las que he participado, indudablemente es posible encontrar muchos pasajes que, si bien no son falsos, podrían aparecer superfluos o aun demostrarse que lo son. ¿'A quién no ha atemorizado Cristo, entre sus fieles, cuando dice: 'En el día del Juicio el hombre dará cuentas de toda palabra inútil que haya pronunciado'? (Mt 12,36) De ahí la recomendación de su apóstol Santiago: "Que cada uno esté dispuesto a escuchar y que sea remiso en hablar" $(S t 1,19)$. Y aquella otra que reza: “... Si alguno no falta en el hablar, es un hombre perfecto" (St3, 1-2). En cuanto a mí, por cierto que no me atribuyo semejante perfección ahora que

\footnotetext{
Cf. De lingua latina VI, 57.

Prov. 10, 19.
} 
soy viejo. Pero aún menos hubiera podido arrogármela cuando, siendo todavía joven, comencé a escribir y a hablar y se me confirió tal crédito que, cada vez que yo me encontraba presente en el momento en que era necesario hablar en público, muy raramente me era concedido callar y escuchar a los demás... ${ }^{4}$

El problema, pues, de la locuacidad no consiste en lo cuantitativo -en lo que haría pensar el prefijo "multi-“" sino en lo cualitativo, es decir que no radica en hablar mucho sino en hacerlo de manera excesiva precisamente en cuanto superflua. Así pues, aun cuando se digan pocas cosas, si ellas son gratuitas, inútiles y/o inoportunas, se está cometiendo un peccatum oris que la tradición posterior prefirió llamar vaniloquium o verbum otiosum. ${ }^{5}$

La cuestión tiene varios aspectos según se examine la caja de resonancia, si se nos permite la expresión, de esta falta que se incluye en los peccata minuta. En primer lugar, la dificultad de medir o de trazar la línea divisoria entre lo mucho y lo excesivo por parte de aquellos que, como los maestros y los predicadores, especialmente, los abogados, tienen por instrumento de oficio la palabra. Éste es el aspecto que Agustín señala aquí, reforzado por un pasaje en el que aconseja desear no verse en la necesidad de hablar, de predicar y enseñar. ${ }^{6}$ De paso, es interesante mencionar que un par de siglos más adelante, Isidoro de Sevilla atribuirá el multiloquium a la incompetencia retórica. ${ }^{7}$

El hablar en demasía da lugar a un extravío cuyo diagnóstico no puede ser más agustiniano. De hecho, en el célebre -y clave- pasaje de Conf. XI, 29, 39, Agustín apela a una de sus estructuras trinitarias, la de los tres movimientos del alma: distentio, intentio, extensio. Según el movimiento de la distentio, el alma se vuelca, se derrama sobre las cosas exteriores, finitas y múltiples, desgarrando su atención, su vital unidad en ellas. Al no dar allí con el bien y la verdad que busca, se vuelve sobre sí misma en el segundo movimiento, el de la intentio. Pero no es esto lo que nos interesa ahora, sino notar que el multiloquium constituye una de las más evidentes manifestaciones y, a la vez, modalidades que asume el movimiento de distentio, esto es, de dispersión del alma cuando ella se extravía en la charla vacua, la vana curiosidad y el "afán de novedades", si se quisiera decirlo a la Heidegger.

\footnotetext{
Retr., Proemium, 2. Todas las traducciones y subrayados son propios.

5 Cf., por ej., Pedro Abelardo, Ep. VIII ad Eloissam.

Cf. En. In Ps. 139, 15.

7 Cf. Sententiae II, 29. Véase allí todo el De sermone.
} 
Sobre esta anulación de la interioridad que se da en el multiloquium, ya se había extendido Ambrosio de Milán, como lo hará después Gregorio Magno. Quien habla mucho -advierten ambos- se dispersa en una múltiple comunicación con el mundo que le impide volver desde él hacia su propio interior, donde, según esta concepción, tiene lugar el verdadero conocimiento. En la locuacidad, la mente humana se derrama como el agua que ya no puede remontarse hacia su fuente; y se convierte en una ciudad desguarnecida e indefensa ante las embestidas del mal, escriben. ${ }^{8}$

Pero la gravedad de las consecuencias de la verborragia o de la vana locuacidad, es decir, de este verbum otiosum, incide de manera muy negativa en la vida social. Efectivamente, el dejarse llevar por el flujo de las palabras ociosas, gratuitas e inoportunas significa deslizarse hacia las dañinas. Quien habla demasiado, suele referirse a asuntos ajenos, y puede caer así fácilmente, en la detracción, en la burla o hasta en la injuria, suscitando litigios que atentan contra la unión y la armonía de la comunidad.

De esta manera, la negligencia en el cuidado de los demás, la indiferencia y la in-curia respecto de los otros en el uso de la palabra, se muestra en toda su gravedad, puesto que es muy probable que desde una mera omisión -que de todos modos no es neutra- se deslice hasta un efectivo perjuicio cometido contra alguien.

En el extremo opuesto al de la locuacidad, pero también como falta, se halla sin duda el "silencio malo", es decir, la taciturnitas que es, por omisión, otro pecado de la lengua, según nos recuerdan Casagrande y Vecchio. Se ha intentado trazar la línea divisoria entre las expresiones silentium malum y mala taciturnitas, términos que muchas veces constituyen sinónimos. Así, por ejemplo, el mismo Gregorio mencionará el silentium malum de los monjes que callan con la boca cuando la Regla lo exige pero cuyo corazón bulle de palabras. ${ }^{9}$ En este caso, el silencio es malo porque le impide alcanzar los verdaderos objetivos de callar que son la escucha tanto exterior cuanto interior de la palabra divina. La taciturnitas, en cambio, tiene límites más amplios que nos interesan más, ya que con ella también se trascienden los muros monacales.

En efecto, la taciturnitas consiste en el no hablar o no hablar lo suficiente cuando se impone hacerlo. Una revisión de sus nefastas consecuencias bastará para delinear mejor sus límites. Esas consecuencias son tanto individuales

\footnotetext{
8 Cf., por ej., San Ambrosio, De Cain et Abel I, 9, 36; Exp. In Ps. 118, 2, 5. Gregorio Magno, Moralia 7, $37,59$.

Cf. Reg. Past. III, 14.
} 
como sociales. En la dimensión individual, el callar demasiado puede inducir a una tempestad interior, a una proliferación de pensamientos y emociones que se desbordan precisamente porque no arriesgan ninguna verificación "objetiva”, ni puesta en tela de juicio por parte de los demás. De esta manera, se puede constituir en resorte moral de la soberbia. Desde otro punto de vista, el psicológico, el obstinarse en callar un dolor agudo aumenta el sufrimiento ulterior y conduce a un encierro en sí mismo peligroso para la salud del alma. Así como el multiloquium disuelve la interioridad, la mala taciturnitas la sobrecarga y la ahoga; el primero malgasta el officium locutionis; la segunda lo niega. ${ }^{10}$

En su dimensión social, el pecado de taciturnitas es, pues, el de la palabra negada, insuficiente o tardía, que no tiene en cuenta el beneficio de los demás. Por eso, les retacea el bien de la corrección, del reproche que ahuyenta el rencor, o del consuelo; se vuelve, entonces, in-solidaria. No hace aquí a la cuestión que más nos importa señalar el hecho de que los textos patrísticos y medievales abundan en la acusación de taciturnitas dirigida a los predicadores indolentes. Entre quienes, por investidura, no tienen esta función, la gravedad de esta falta radica en que con ella se escatima ayuda, exhortación, consejo al semejante. Más aún, Casiano menciona el caso del silencio utilizado como instrumento de burla hacia otra persona. ${ }^{11}$

Pero no olvidemos que esta falta no sólo lo es cualitativamente, también puede serlo desde el punto de vista cuantitativo. Puede que se trate de un silencio excesivo, esto es, de nimia taciturnitas, por ejemplo, el callar cuando se está difamando a alguien.

Como se verá hacia el final, ésta y otras consideraciones sobre el tema confluyen en una misma fuente doctrinal, la agustiniana. Sea como fuere, la oportunidad de callar y de hablar, y, en este último caso, el conocimiento de qué decir dependen de la sabiduría.

Ahora bien, la sabiduría, comoquiera que se la defina, tiene como componente esencial la prudencia, en el sentido de la vieja sophrosýne de los griegos, lo cual implica comprensión, puesto que consiste en cierta racionalidad práctica. Y ésta -ya se sabe- no se aprende de manera argumentativa y/o libresca. Decidir acertadamente cuándo callar y cuándo hablar es, pues, propio del sabio. Y, cuando ese acierto es puesto al servicio del prójimo más

\footnotetext{
${ }^{10}$ Cf. op.cit. p. 443 (nota 2).

11 Cf. Coll. XVI, 18.
} 
inmediatamente próximo, se torna elemento fundamental de la amistad. Con todo, señala Agustín que “...la amistad no se debe circunscribir en límites estrechos, puesto que ha de comprender a todos aquellos a quien se debe afecto y amor [es decir, a los semejantes en cuanto tales], aun cuando se dirija con más propensión a algunos..."12

No podemos detenernos en el tema de la affabilitas; nos importa más la amicitia en el sentido clásico del término, ése que Agustín hereda de Cicerón.

$$
* * *
$$

Así pues, prescindiremos de la cuestión -también mencionada por él- de la amistad con Dios para atenernos exclusivamente a esa relación particular que se da entre los seres humanos. En tal sentido, diríamos que hay núcleos en el tratamiento teórico que Agustín hace al respecto, ciertamente, de manera no sistemática. Considerando las apariciones significativas del tema, es decir cómo éste asoma en la totalidad de la obra agustiniana, se tendrían, cronológicamente consideradas, las siguientes menciones:

1) una en Contra Academicos (386)

2) dos en Soliloquia (387)

3) otra en De fide rerum quae non videntur (399)

4) varias en Confessiones (400)

5) un par de ellas en De civitate Dei (413-426)

Lo primero a tener en cuenta es que Agustín recoge y hace propia la afirmación ciceroniana ya en el Contra Academicos: "Del modo más recto y justo la amistad ha sido definida como 'la comunicación, mediante la benevolencia y el amor, de cosas humanas y divinas". ${ }^{13}$ Tres elementos se destacan aquí: la comunicación, el amor y la benevolencia como razón y modo de esa comunicación, y su contenido constituido por las cosas comunes a todos los hombres y también por aquellas referidas a lo divino, esto es, a lo que los

12 Ep. 130, 6, 13.

13 Contra Acad. III, 6, 13. La cita de Cicerón corresponde a Lael. 6. 20. 
trasciende. En los Soliloquios, en cambio, aparece la referencia bíblica de Levítico 19,18 de amar al amigo ni más ni menos que como a sí mismo. ${ }^{14} \mathrm{Al}$ mismo tiempo, también se incita allí a conocer al amigo, aun cuando es posible que éste se ignore a sí mismo. Más todavía: Agustín plantea la dicha de la compañía de los amigos "para poder indagar en concorde colaboración sobre nuestra alma y sobre Dios", ${ }^{15}$ es decir sobre lo que constituía sus preocupaciones excluyentes. Ciertamente, en Sobre la fe en lo que no se ve, el hiponense hace suya la común opinión acerca de que es indudable que se puede tener un amigo también en la prosperidad, aunque es en la tribulación cuando tenemos la prueba más cierta de su amistad. Con todo, antes de que se vea sometida a prueba, creemos en ella. ${ }^{16}$ Por fin, en uno de los últimos libros escritos por él en La Ciudad de Dios, no podía faltar el tema de la amistad, puesto que el XIX está particularmente dedicado a la vida social. Señala allí Agustín las angustias propias del contar con amigos amados, ya sea por los males físicos y morales que tememos les sobrevengan, ya sea por el hecho de que nos abandonen al morir.

Pero, de todos los que se han mencionado, ningún texto es tan rico en esta materia como el de Las Confesiones. En una de sus páginas inolvidables Agustín relata la experiencia de la muerte de un amigo de la infancia a quien lo había seguido uniendo después, cuando vuelve a enseñar a su tierra, "el fervor de las aficiones compartidas":

Con ese dolor se entenebreció mi corazón y cuanto miraba era muerte. La patria era un suplicio para mí, y la casa paterna, una extraña desdicha. Todo lo que con él había compartido, sin él se volvía una cruel tortura. Por todas partes lo buscaban mis ojos y no les era dado. Odié todas las cosas, porque no lo tenían ni podían decirme como antes, como cuando estaba ausente y volvía: "Mira, aquí viene". Yo me había convertido en una gran cuestión para mí mismo y le preguntaba a mi alma por qué estaba triste y me conmovía tanto, y ella no sabía responderme nada... ${ }^{17}$

Con todo, la muerte de este ser querido signa para Agustín el fin de una experiencia de la que se muestra cabalmente consciente. Se pretende decir con esto que aun a la distancia, en este intento de re-significación que son

\footnotetext{
14 "Diliges amicum tuum sicut teipsum" en la versión de la Vulgata.

15 Soliloquios, I, 3, 8 y 12, 20, respectivamente.

${ }^{16}$ Cf. De fide rerum quae non videntur 1,2 y 2,3 .

17 Conf. IV, 4, 9.
} 
las Confesiones, Agustín pondera los matices que asumió esa relación. Por eso, describe, por ejemplo, las reacciones de su amigo pero, sobre todo, las propias.

Hay en ese texto, en cambio, otros pasajes en los que, por así decir, Agustín no es tanto sujeto sino objeto y beneficiario de amistad, o sea, de esa relación de comunicación benevolente entre los hombres. Por serlo, ella se puede ver en lo que hoy llamaríamos "términos gestálticos", es decir, una relación en la que cualquiera de las personas involucradas se hace cargo, en algunas ocasiones, del papel y la función de figura, mientras que en otras asume los del fondo.

$$
* * *
$$

Esos pasajes se encuentran en el libro VIII de las Confesiones, en el que culmina, con la crisis final, el proceso de conversión interior cuya narración se inicia en el VI. Recordemos que Agustín se encuentra en una propiedad prestada en Casicíaco, acompañado de su madre y de amigos, jóvenes colegas que compartían sus inquietudes intelectuales y su búsqueda por el sentido de la vida.

Entre ellos está Nebridio y también Alipio. Mientras el primero se encuentra temporalmente ausente, Alipio y Agustín reciben la visita de Ponticiano quien les narra la conversión al Cristianismo de otros hombres. Aparentemente y, a juzgar al menos por el relato agustiniano de Confesiones, Alipio guarda silencio, el silencio de quien rumia sus propias conclusiones ante un giro tan dramático en una vida humana, el silencio de quien respeta también con ello y mientras tanto la reflexión ajena ante el mismo relato.

Lo cierto es que, como es sabido, ese relato enfrenta a Agustín con el dilema interior de entregarse a la fe o continuar con sus planes de vida. De esta manera, habiendo salido Ponticiano, él entra en sí mismo y se enfrenta a la decisión:

Entonces, en medio de aquel gran combate de mi casa interior, que yo había suscitado violentamente con mi alma, en lo más recóndito que tenemos, en mi corazón, con el rostro y el espíritu alterados, me dirigí a Alipio y exclamé: ¿Qué nos pasa? ¿Qué es esto que escuchaste? Los que no son doctos se elevan y arrebatan el cielo y nosotros, con todo nuestro saber, faltos de corazón, jmira dónde nos estamos revolcando, en la carne y en la sangre! ¿Es que acaso nos da vergüenza seguirlos, porque nos han precedido, pero no nos la da el no 
seguirlos al menos?’ No sé qué otras cosas parecidas dije, y esa tormenta me apartó de su lado, mientras él, atónito, me miraba en silencio. ${ }^{18}$

Veamos qué notas presenta la descripción agustiniana de esta crisis y la cuidadosa actitud de Alipio en la escena. Primero, tal crisis tiene lugar en el corazón, que Agustín caracteriza como "lo más recóndito que tenemos". Así pues, el cor señala en sus escritos la más profunda interioridad y es sede de los pensamientos, no de las emociones. ${ }^{19}$ Segundo, la tempestad del corazón se desata en un torrente de palabras de cuya totalidad ni siquiera se tiene memoria. Téngase presente, de paso, que hacer precisamente lo contrario, es decir, no desahogar verbalmente las tormentas interiores es una de las contraindicaciones terapéuticas de la taciturnitas, como mal silencio. Tercero, la primera reacción de Alipio, como testigo y compañía de este momento, es la de guardar silencio, mientras Agustín procura alejarse. Pero con la acotación "atónito", el texto indica claramente que este callar de Alipio obedece, en primera instancia, a su sorpresa ante la vehemencia de la reacción agustiniana. El pasaje continúa diciendo:

En la casa en la que nos hospedábamos había un pequeño huerto, del que nosotros hacíamos uso, así como del resto de la casa, por no habitarla el dueño. Allí me llevó la tempestad desatada en mi pecho, para que nadie estorbara el ardiente combate que yo había entablado conmigo mismo, hasta que se dirimiera como Tú, Señor, sabías y yo ignoraba [...] Me retiré, pues, al huerto y siguió mis pasos Alipio [...] ¿Y cómo me habría abandonado él estando yo tan afectado? [...] Esta contienda en mi corazón no era sino la de mí mismo contra mí mismo. Y Alipio, inmóvil a mi lado, esperaba en silencio el desenlace de aquella inusitada agitación. ${ }^{20}$

Digamos, de paso, que aquí la tempestad interior que se ha desatado aparece como teniendo sede en el pecho (in pectore). La razón de ello es que, cuando en la profundidad del corazón los pensamientos acerca del propio destino entran en debate, esa agitación encuentra su correlato afectivo, se traslada a las

\footnotetext{
${ }^{18}$ Conf. VIII, 8, 19.

19 Véase la vieja y famosa comunicación de Anton Maxsein al Congreso Internacional Agustiniano de 1954 publicada como "Philosophia cordis bei Augustinus", en Augustinus Magister. Vol. I, Paris, 1954, pp. 357-371.

${ }^{20}$ Conf. VIII, 11, 27.
} 
emociones, y, en las imágenes que suele usar Agustín, es el pecho justamente la sede de las afecciones. ${ }^{21}$

Pero sigamos atendiendo a los gestos de Alipio en este pasaje, al cuidado que procura, mediante la administración de la palabra, a Agustín. Si fue el estupor lo que lo llevó a callar en un primer momento, este segundo momento es el del silentium bonum, puesto que es el silencio solidario: no se aparta de su amigo; permanece -Agustín lo dice de manera taxativa- "inmóvil a su lado", porque percibe el peligro de un descontrol emotivo. Pero hay más en esta suerte de tempestad:

...para que estallara por completo, también con voces, me levanté y me aparté de Alipio: me parecía que la soledad era más apta para llorar. Y me retiré lo más lejos que pude, con el fin de que no me pesara su presencia. Ése era el estado en que me encontraba. Él lo advirtió, pues yo le había dicho, creo, no sé qué palabras en las que el sonido de mi voz ya parecía preñado de llanto. ${ }^{22}$

Decíamos, y el mismo Agustín insistirá más tarde en ello, que ejercer virtuosamente la palabra dirigida a los amigos requiere una sabiduría práctica cuya base es la prudencia basada en la comprensión. Alipio advirtió-como se ve, el texto lo dice con toda claridad- la necesidad de esperar calladamente la superación del momento álgido en la crisis agustiniana.

Pero, si en la virtud de la palabra amiga de un lado está el acierto del buen silencio, del otro se encuentra el acierto en el ejercicio del officium locutionis. Si, según el testimonio agustiniano, Alipio supo cuándo y cómo callar, también supo cuándo y cómo hablar ante su semejante, su amigo y su camarada de ruta en la búsqueda del sentido de la vida. Como se sabe, la resolución de esta crisis está marcada por la lectura que hace Agustín de la Carta de Pablo a los Corintios, 13, 13:

Así que volví a todo correr al lugar donde estaba sentado Alipio y en el que, al levantarme, yo había dejado el libro del apóstol. Lo tomé, lo abrí y leí en silencio el primer capítulo que cayó bajo mis ojos ['… revestíos del Señor Jesucristo y “... no os deis a la carne para satisfacer sus deseos']. No quise leer más; no era necesario. No bien llegué al fin del pasaje, como si una luz

\footnotetext{
21 Oscar Velásquez Gallardo: Tumultus pectoris: el espacio vital de las afecciones en las Confesiones de Agustín. En: De las pasiones en la Filosofía Medieval, Pontifica Universidad Católica Chile - SIEPM, Santiago de Chile, 2009, pp. 61-68.

22 Conf. VIII, 12, 28.
} 
de seguridad se infundiera en mi corazón, se disiparon todas las tinieblas de la duda.

Entonces... cerré el libro y ya con mejor semblante me confié a Alipio. Él, a su vez, me manifestó lo que pasaba en su interior y que yo desconocía. Pidió ver el pasaje; se lo mostré y puso atención también a lo que se decía más adelante. Yo ignoraba lo que seguía. Y seguía así: "Acoged al débil en la fe”. Me hizo saber [aperuit] que esto él se lo aplicaba a sí mismo. En todo caso, esta admonición lo fortaleció en la decisión y el propósito de virtud, en todo conformes a sus costumbres en las que ya hacía tiempo me aventajaba muchísimo. Y sin turbación ni vacilación alguna se me unió. ${ }^{23}$

Hasta entonces, Alipio había seguido firme en su puesto de vigía silencioso, en la cura proximi. Ahora el silentium bonum del amigo da lugar a la palabra justa. En la misma línea de benevolencia que sostiene el callar y el hablar se da esa comunicación de la que habla Cicerón en la definición de amistad que de él recoge Agustín. Por lo demás, Alipio responde cabalmente a ese concepto al poner como contenido de tal comunicación las cosas humanas -el desgarro del corazón, el llanto que desahoga el pecho- y las divinas, que se dan al acompañarlo a través de una lectura común de la Escritura.

Cuando Alipio advierte que ha llegado a su fin la instancia más dramática en la sorda lucha que Agustín sostenía consigo mismo para resistirse a Dios, en ese momento y sólo entonces, reasume la voz amiga. La palabra de Alipio ejerce así de la mejor manera el officium locutionis: es oportuna y generosa, esto es, cuidadosa del otro. La oportunidad se hace presente en el hecho de que no impone protagonismo alguno, no intenta interferir en el tenso diálogo entre el llamado divino y la angustiada resistencia agustiniana; de haberlo hecho, quizás habría usado la vacilación del amigo para zanjar la propia. Pero la palabra de Alipio es también generosa, no sólo en la escucha sino en el habla, o sea, en cuanto comparte lo que hay en su corazón, lo más íntimo del alma, para revelarle al amigo que no está solo en la ruta que ambos acaban de emprender.

Así, Alipio se une a quien es su semejante en la dimensión natural -"me manifestó lo que pasaba en su interior"- y ya también en la espiritual, acompañando a su par en la convalecencia -"la admonición paulina lo 
fortaleció en la decisión"-. Y, una vez más, el cuidado del otro redunda en el cuidado de sí mismo.

Años más tarde el ya obispo de Hipona, al explicar ante sus fieles un salmo, dice que no es bueno no hablar nunca sino cuando lo requiere el officium locutionis. Y añade que conviene conservar el deseo de gozar del silencio, pero, siempre que la necesidad lo requiera, hay que tener pronta la palabra de la sabiduría. ${ }^{24}$

¿Habrá recordado, es decir, habrá tenido Agustín a Alipio en su corazón al escribir esto? Quizá sí.

24 "Itaque, fratres, cito dixerim Caritati vestrae, ubi unusquisque probet se: non ut non loquatur, sed ut de illo locutionis officium exigat; gaudium autem taciturnitatis habeat in voluntate, vocem doctrinae in necessitate". En in Ps. 139, 15. 